\title{
Concentrations of faecal immunoreactive progestagen metabolites during the oestrous cycle and pregnancy in the black rhinoceros (Diceros bicornis michaeli)
}

\author{
F. Schwarzenberger ${ }^{1}$, R. Francke ${ }^{2 *}$ and R. Göltenboth ${ }^{2}$ \\ ${ }^{1}$ Institut f. Biochemie, Vet. Med. Univ. Wien, Linke Bahngasse 11, A-1030 Vienna, Austria; and \\ ${ }^{2}$ Zoologischer Garten Berlin, Hardenbergplatz 8, D-1000 Berlin 30, Germany
}

\begin{abstract}
The analysis of reproductive hormones in faecal samples is a possibility for non-invasive monitoring of reproductive status in free-ranging or intractable species. In the present study, faecal samples from three black rhinoceroses (Diceros bicornis michaeli) were collected at about weekly intervals during oestrous cycles and pregnancy. Daily samples were taken during the week after parturition. Total immunoreactive progestagens in faecal extracts were analysed with three different enzymeimmunoassays (EIA) that had considerable specificity for progestagens containing either a $20 \alpha$-hydroxyl or a 20 -keto group. With each EIA it was possible to distinguish between the follicular and luteal phases of the oestrous cycle. Mating corresponded with low concentrations of faecal progestagens. Samples from five and six consecutive cycles were available from two rhinoceroses and cycle lengths of 24 and 26.5 days were calculated. All three animals became pregnant and the duration of gestation ranged from 440 to 470 days. After fertilization, the concentration of progestagens increased continuously, as in the luteal phase, reaching values 5-10 times higher between days 60 and 250. During the two weeks before parturition faecal progestagens declined and within 3-4 days post partum had reached follicular phase values. It was concluded that several immunoreactive progestagens are present in the faeces of black rhinoceroses and that their measurement with EIA enables non-invasive monitoring of the oestrous cycle and pregnancy.
\end{abstract}

\section{Introduction}

The two subspecies of the African black rhinoceros, the eastern (Diceros bicornis michaeli) and the southern (Diceros bicornis minor), are endangered owing to continued poaching. The African population was about 65000 animals in 1970 (Kock et al. 1991) but by the end of 1990, the total number of animals had declined to about 3000 in the wild and 204 in captivity (Klös and Frese, 1991). Zoological gardens are making great efforts to breed their populations to secure the survival of this species. However, this goal and also future prospects for using artificial insemination, superovulation or embryo transfer face restrictions from a lack of basic information on the reproductive biology of the black rhinoceros.

In a recent study, single blood samples from several black rhinoceroses were collected during a relocation programme in Zimbabwe and assayed for gonadotrophins and steroid hormones (Kock et al., 1991). However, the possibility of regular blood sampling from rhinoceroses is restricted and, therefore, non-invasive urine or faecal sampling might be more appropriate for endocrine investigations. The measurement of reproductive hormones in urine samples is a widely applied technique

${ }^{*}$ Present address: Kurze Str. 1, D-6600 Saarbrücken 3, Germany. Received 3 September 1992. and used for many different species, such as primates (Graham et al., 1972; Hodges and Green, 1989), the okapi and giraffe (Loskutoff et al., 1986) and tapir (Kasman et al., 1985). It has also been used for investigations in Indian (Kassam and Lasley, 1981; Kasman et al., 1986; Hodges and Green, 1989) and African rhinoceroses (Ramsay et al., 1987; Hodges and Green, 1989; Hindle et al., 1992). Nevertheless, there are practical difficulties in recovering urine samples from free ranging animals. Therefore, an increasing number of investigators have used faecal steroid hormone analysis as an alternative for monitoring ovarian function and pregnancy. Such studies have been described for various domestic and wildlife species including horses (Möstl et al., 1983; Bamberg et al., 1984; Kirkpatrick et al., 1991; Lucas et al., 1991; Schwarzenberger et al., 1991, 1992), pigs (Choi et al., 1987), cows and muskoxen (Desaulniers et al., 1989), caribou (Messier et al., 1990), various zoo animals (SafarHermann et al., 1987; Bamberg et al., 1991) and different species of ape (Wasser et al., 1991).

Since the administration of radioactively labelled steroid hormones into the blood of a white rhinoceros has proved that excretion in the faeces is as important as in the urine (Hindle and Hodges, 1990), the measurement of progestagens in faeces of rhinoceroses may be appropriate for monitoring reproductive function. In this study, the presence of several progestagen metabolites in faecal samples of the black rhinoceros was 
demonstrated and they were measured as total immunoreactive progestagens during the oestrous cycle, pregnancy and the post partum period.

\section{Materials and Methods}

\section{Animals}

Three female black rhinoceroses (Diceros bicornis michaeli) (Mzima, Kilaguni, Theluji) from the Zoologischer Garten Berlin AG were housed individually in temperature-controlled stables $\left(16-22^{\circ} \mathrm{C}\right)$ at night and during the day they were enclosed in separate outdoor pens. During winter a cycle of $10 \mathrm{~h}$ light: $14 \mathrm{~h}$ dark was maintained indoors. The rhinoceroses were fed with hay, alfalfa-hay, grass and special pellets (Mazuri food). Additionally, leaves, branches, different fruit and vegetables were given. The animals had free access to water and were given supplementary vitamin $\mathrm{E}$ daily.

The breeding records for 'Mzima' (born 1973, Kenya) showed that she had three calves between 1982 and 1987 and one abortion in December 1988. 'Kilaguni' (born 1974, Kenya) had one live offspring in 1986, and 'Theluii' (born December 1981, Zoo Berlin) had no previous pregnancy. During the daytime, the females were sequentially penned with a male black rhinoceros of proven fertility. All three females became pregnant; the matings that led to conception were observed for 'Theluji' and 'Kilaguni'. They calved on 12 December 1990 and 7 February 1991, respectively; 'Mzima' calved on the 4 April 1991.

\section{Collection of faecal samples}

Faecal samples were collected off the ground by the keepers during the morning work in the stalls. From May 1989 until three months after calving a total of 113,123 and 91 samples were collected from 'Mzima', 'Kilaguni' and 'Theluji', respectively. During the oestrous cycles and in the first half of pregnancy, samples were collected about once a week and during the second half of pregnancy at about every 2 weeks. Additionally, daily samples from 'Kilaguni' were available for the last two weeks of pregnancy and from all three animals for the first week after parturition. From then on, samples were collected twice a week for 3 months. Samples were stored at $-20^{\circ} \mathrm{C}$ and shipped to Vienna at 2- to 3-month intervals, where they were stored under the same conditions.

\section{Extraction and analysis by enzymeimmunoassay}

The extraction of the faecal samples and the protocols for the enzymeimmunoassays (EIA) were as described by Schwarzenberger et al. (1991). Briefly, $0.5 \mathrm{~g}$ faeces were extracted with $4.5 \mathrm{ml}$ aqueous methanol and defatted with petroleum benzene. The methanol was diluted and analysed with the EIA. The EIA used a double-antibody technique and were performed in microtitre plates, which were coated with an antibody against $\operatorname{IgG}$. After overnight incubation of standards, samples, steroid antibody and enzyme label, the plates were emptied and washed before the substrate was added. The enzymatic reaction was stopped with $\mathrm{H}_{2} \mathrm{SO}_{4}$, the optical density recorded and the hormone concentrations calculated.

Faecal sample extracts were analysed without prior chromatographic separation. However, HPLC separation of faecal extracts and subsequent analysis of the fractions with EIA revealed the presence of several immunoreactive progestagens. Therefore, the results were considered as measurement of total immunoreactive progestagens. Although each EIA reacted with several immunoreactive progestagens, each assay had considerable specificity for steroids containing either a $20 \alpha$ hydroxyl, a $20 \beta$-hydroxyl- or a 20 -keto group. The progestagens with a $20 \alpha-\mathrm{OH}$ group were measured by two different EIA, one of which used an antibody for 20a-dihydroprogesterone (20 $\alpha$-progestagens) and the other for pregnanediol (Pdprogestagens); progestagens containing a $20 \beta-\mathrm{OH}$ group (20ßprogestagens) or a 20-keto group (20-keto-progestagens) were measured with antibodies for $20 \beta$-dihydroprogesterone and for progesterone, respectively. The EIA for $20 \alpha$ - and $20 \beta$ progestagens were as described by Schwarzenberger et al. (1991). Serial dilutions of faecal extracts gave displacement curves parallel to the standard curves of EIA for the 200-progestagens, the Pd-progestagens and the 20-keto-progestagens.

The antibody for the assay of $\mathrm{Pd}$-progestagens was raised in sheep against $5 \beta$-pregnane-3 $\alpha, 20 \alpha$-diol-3-glucuronide: ovalbumin. It was purchased from P. Samarajeewa (University College, London). The coating antibody was produced in rabbits against sheep IgG and kindly donated by $A$. G. Kanout (Bundesanstalt für Tierseuchenbekämpfung, Mödling, Austria). The enzyme label was the same as for the 20a-progestagen EIA (4-pregnen-20 $\alpha$-ol-3-one-3-CMO:horseradish peroxidase; Schwarzenberger $e$ t al., 1991). Antibody and enzyme label dilutions were 1:90 000 and 1:10000, respectively. The standard curve was prepared with $5 \beta$-pregnane-3 $\alpha, 20 \alpha$-diol and ranged from 2 to $500 \mathrm{pg}$ per well. Its $50 \%$ intercept was $110 \pm 19 \mathrm{pg}$ (mean $\pm \mathrm{SD}$ ). The intra-and interassay coefficients of variation for a pool of faecal samples were 13.2 and $19.0 \%$, respectively. The EIA showed the following crossreactions (steroids purchased from Steraloids Ltd, Wilton, $\mathrm{NH}$, or Sigma Ltd, St Louis, MO): $5 \beta$-pregnan-20 $\alpha$-ol-3-one (176\%), 4-pregnen-20 $\alpha$ ol-3-one (150\%), $5 \beta$-pregnane-3 $\alpha, 20 \alpha$-diol ( $100 \%$ ), $5 \beta$-pregnane$3 \beta, 20 \alpha$-diol $(100 \%)$, $5 \alpha$-pregnane- $3 \beta, 20 \alpha$-diol $(55.6 \%), 5 \alpha$ -

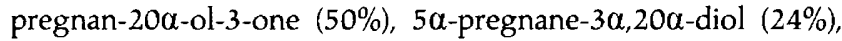
5 -pregnene-3 $3,20 \alpha$-diol (16.6\%), 4-pregnen-20 $\beta$-ol-3-one (2.1\%). All other steroids tested crossreacted less than $1 \%$.

The antibody and enzyme label for the EIA of 20-ketoprogestagens were kindly donated by E. Möstl (Vet. Med. Univ., Vienna). The antibody was raised in rabbits against 4pregnen-6 $\alpha$-ol-3,20-dione-6HS:BSA from Steraloids Ltd. The enzyme label was produced with 4-pregnene-3,20-dione-3CMO and horseradish peroxidase as described by Schwarzenberger $e t$ al. (1991). Antibody and enzyme label dilutions were 1:25000 and 1:1000, respectively. The standard curve, which ranged from 2 to $500 \mathrm{pg}$, was prepared with 4-pregnene-3,20-dione and had a $50 \%$ intercept of $48 \pm 18 \mathrm{pg}$ (mean $\pm \mathrm{SD}$ ). The intraand interassay coefficients of variation were 10.2 and $18.6 \%$, respectively. The following crossreactions were observed: 4pregnene-3,20-dione (100\%), $5 \beta$-pregnane-3,20-dione $(71 \%), 5 \alpha$ pregnane-3,20-dione $(40 \%)$, 5-pregnen-3 $\beta$-ol-20-one $(28.6 \%)$, $5 \alpha$-pregnan-3 $\beta$-ol-20-one $(18.2 \%), \quad 5 \beta$-pregnan- $3 \beta$-ol-20-one 


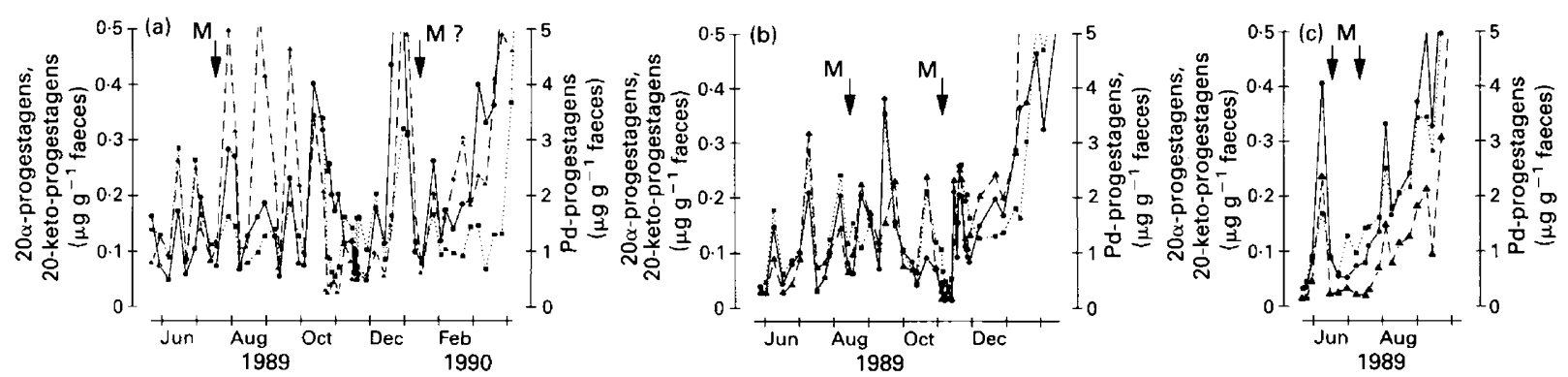

Fig. 1. Concentrations of total immunoreactive progestagens in faecal samples from three black rhinoceroses (a) 'Mzima'; (b) 'Kilaguni'; (c) 'Theluji' during oestrous cycles and the first 80 days of pregnancy. Determined by enzymeimmunoassay (- - ) 20aProgestagens; ( ….) Pd-progestagens (Pd-Pgs); (- $\mathbf{A}--)$ 20-keto-progestagens. M: observed mating, Mr: estimated time of mating.
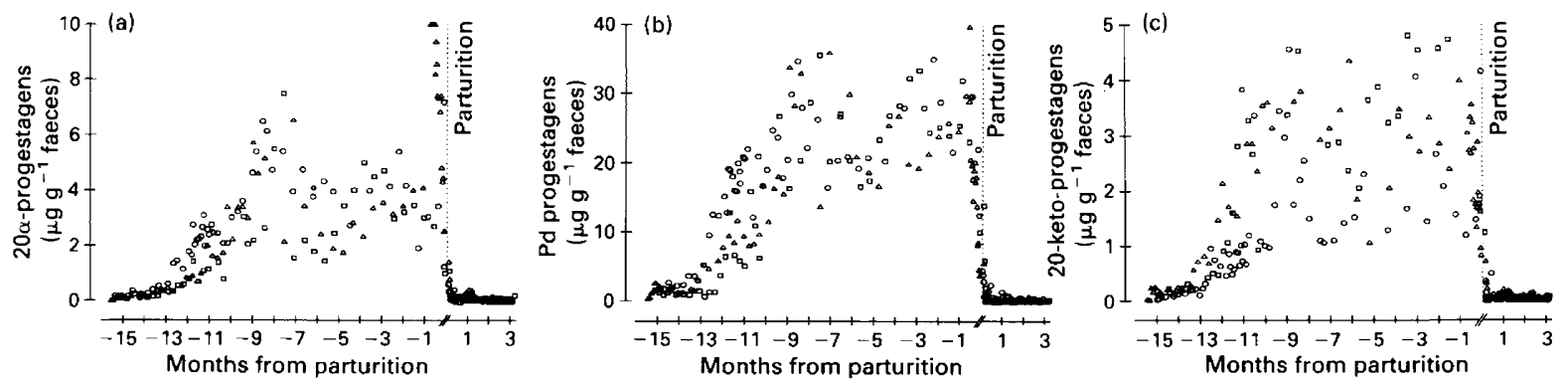

Fig. 2. Concentrations of total immunoreactive progestagens in faecal samples of three black rhinoceroses ( $\square$ 'Mzima', $\triangle$ 'Kilaguni', $O$ 'Theluji') during pregnancy and the first three months post partum. Determined by enzymeimmunoassay (a) 20 $\alpha$-progestagens; (b) Pd-progestagens (Pd-Pgs); (c) 20-keto-progestagens.

(6.5\%), 4-pregnen-20 $\alpha$-ol-3-one $(6.3 \%), 5 \beta$-pregnan-3 $\alpha$-ol-20one $(3.3 \%)$. All other steroids tested crossreacted less than $1 \%$.

\section{HPLC of faecal immunoreactive progestagens}

To obtain information on polarity and indications on the possible structure of the immunoreactive steroids in faeces, samples from 'Theluji' taken during the follicular and luteal phase of the oestrous cycle and from each third of pregnancy were chromatographed. The samples were mixed with $\left[{ }^{3} \mathrm{H}\right]$ progesterone and $\left[{ }^{3} \mathrm{H}\right] 20 \alpha$-dihydroprogesterone, extracted, separated on HPLC (silica 60 column) using a linear solvent gradient of $0-6 \%$ methanol in $n$-hexane:chloroform $(7: 3 \mathrm{v}: \mathrm{v})$ and the fractions analysed with the EIA (Schwarzenberger $e$ t al., 1991). The retention times of different crossreacting steroids were determined and compared with those of the immunoreactive fractions.

\section{Results}

\section{Oestrous cycle}

All samples from the first shipment sent to Vienna were analysed with the EIA for 20a-, Pd-, 20-keto- and 20 progestagens. Since $20 \beta$-progestagens were not detectable in these samples, this assay was not used for subsequent samples. The faecal concentrations of $20 \alpha$-, $\mathrm{Pd}$ - and 20-keto-progestagens during the oestrous cycles and the first 80 days after conception are given (Fig. 1a-c). In general, the different progestagens showed parallel patterns, and mating corresponded to values of $<75,<1000$ and $<100 \mathrm{ng} \mathrm{g}^{-1}$ faeces for $20 \alpha-, \mathrm{Pd}$ - and 20keto-progestagens, respectively. These values were considered as representative for the follicular phase. The concentrations remained low for more than 5 days after mating, then increased to luteal phase concentrations, which were considered as concentrations of $>150,>1500$ and $>150 \mathrm{ng} \mathrm{g^{-1 }}$ faeces for $20 \alpha$-, Pd- and 20-keto-progestagens, respectively. On the basis of these assumptions, 'Mzima' (Fig. 1a) had five cycles from June until the beginning of October. By dividing this number into the time, an average cycle length of 24 days was calculated. Between October and December 'Mzima's' ovarian activity was more erratic and, therefore, not included in calculations of cycle length. Luteal phase concentrations of 20-keto-progestagens for 'Mzima' were higher than those of the other two animals. From mid-January onwards her faecal progestagen concentrations increased, suggesting that she had become pregnant in the first half of January. 'Kilaguni' (Fig. Ib) had six cycles with an average cycle length of 26.5 days from June until the beginning of November. She showed low faecal 20a-progestagen concentrations in October, but her 20-keto-progestagen and $\mathrm{Pd}$ progestagen concentrations suggested a luteal phase. 'Theluji' (Fig. Ic) displayed one luteal phase before matings in June and July. Between these two matings, the progestagen concentrations remained in the follicular phase range and, therefore, the mating in July was used in the calculation of gestational length.

\section{Gestation and postpartum period}

The different progestagen values during pregnancy were plotted with respect to parturition (Fig. 2a-c). Gestational lengths 
for 'Theluji' and 'Kilaguni' were 459 and 470 days, respectively. On the basis of faecal hormone measurements gestational length was estimated to be 440-454 days for 'Mzima'. All three rhinoceroses delivered live, female calves.

Within 10 days after mating, faecal progestagen values had increased to luteal phase concentrations. They decreased slightly, in all three animals, between 3 and 4 weeks after fertilization, but remained, in contrast to non-fertile cycles, in luteal phase ranges. Thereafter, they increased again, with a sharp and continuous increment occurring between days 5060 and days $200-250$ of pregnancy, when the $20 \alpha$ - and Pdprogestagens reached their first peak. Between days 250 and 400 , faecal progestagen values were about 5-10 times higher than during the luteal phase of the oestrous cycle. The $20 \alpha$ progestagens and $\mathrm{Pd}$-progestagens tended to peak for a second time prior to parturition. During the last 2 weeks of pregnancy, progestagen concentrations in the daily faecal samples of 'Kilaguni' declined continuously. Parturition in all three animals occurred in the presence of significant amounts of faecal progestagens. Concentrations declined to follicular phase values within 3-4 days post partum and remained in this range for the following 3 months, except for 'Theluji' at 7-14 days post partum and for 'Kilaguni' at 22-36 days when luteal phase concentrations were recorded.

\section{HPLC separation of faecal immunoreactive progestagens}

After HPLC separation of faecal extracts and subsequent analysis of the fractions with the EIA, several immunoreactive peaks were detected. In general, analysis with the EIA for 20 $\alpha$ - and Pd-progestagens showed the same pattern for the distribution of immunoreactivity in the fractions, whereas the 20 -keto-progestagens showed distinct differences. The sum of the different immunoreactive fractions for each particular EIA was similar to the value obtained in the matched assay without prior chromatography, after correcting for recovery $(60 \%)$ of added $\left[{ }^{3} \mathrm{H}\right]$ steroids. During the follicular phase the progestagen concentrations were near the detection limit of the methods (data not shown). During the luteal phase of the oestrous cycle (Fig. 3) several immunoreactive peaks eluted within the first 30 fractions, but only small amounts coeluted with $\left[{ }^{3} \mathrm{H}\right]$ progesterone and $\left[{ }^{3} \mathrm{H}\right] 20 \alpha$-dihydroprogesterone. The 20a-progestagen and Pd-progestagen peaks (Figs 3 and 4) showed retention times similar to the following standards: a: $5 \alpha$-pregnan-20 $\alpha$-ol-3-one; b: $5 \beta$-pregnan-20 $\alpha$-ol-3-one; c, d: $5 \alpha$-pregnane- $3 \alpha / \beta, 20 \alpha$-diol, $5 \beta$-pregnane-3 $\beta, 20 \alpha$-diol and 5 -pregnene- $3 \beta, 20 \alpha$-diol; e: $5 \beta$ pregnane-3 $2,20 \alpha$-diol; whereas the 20-keto-progestagens; $f$ and $\mathrm{g}$ eluted like $5 \alpha$-pregnane-3,20-dione, $5 \alpha$-pregnan-3 $\alpha$ ol-20-one and $5 \alpha$-pregnan- $3 \beta$-ol-20-one, respectively. In pregnancy (only last third of pregnancy shown, Fig. 4) several additional and more polar peaks, eluting between fractions 30 and 60 appeared. As seen from samples of different stages of pregnancy, these peaks became more prominent as pregnancy progressed and the relative proportions of peaks ' $\mathrm{d}$ ' and ' $\mathrm{e}$ ' increased, whereas that of the less polar peak 'a' decreased. In pregnancy samples, immunoreactive substances coeluting with $\left[{ }^{3} \mathrm{H}\right]$ progesterone and $\left[{ }^{3} \mathrm{H}\right] 20 \alpha$-dihydroprogesterone were either at or below the detection limit of the method.

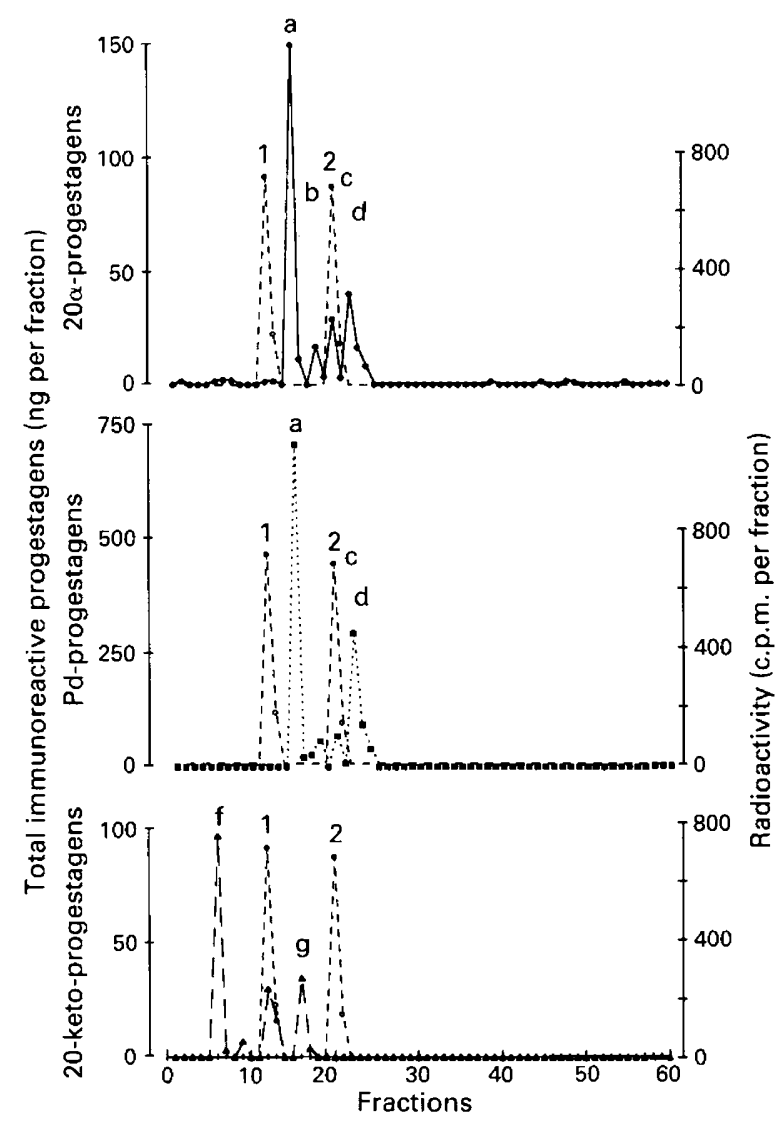

Fig. 3. Total immunoreactive progestagens during the luteal phase of the oestrous cycle in a faecal sample from a black rhinoceros after HPLC separation and subsequent analysis of the fractions with three different enzymeimmunoassays (-O $-20 \alpha$-progestagens; $(\cdots \mathbf{D} \cdots)$ Pd-progestagens; (- $\mathbf{A}--)$ 20-keto-progestagens. Concentrations are ng per fraction calculated for $\mathrm{I} g$ of faeces without correction for methodological losses. $\left[{ }^{3} \mathrm{H}\right]$ steroids (--O--) determined by liquid scintillation counting, I: $\left[{ }^{3} \mathrm{H}\right]$ progesterone; 2: $\left[{ }^{3} \mathrm{H}\right] 20 \alpha$-dihydroprogesterone. The retention times of the immunoreactive peaks $(\mathrm{a}-\mathrm{g})$ were compared to those of different steroid standards (a) 5- $\alpha$-pregnan-

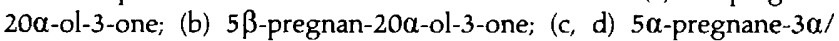
$\beta, 20 \alpha$-diol, $5 \beta$-pregnane- $3 \beta, 20 \alpha$-diol and 5 -pregnene-3 $\beta, 20 \alpha$-diol; whereas the 20-keto-progestagens eluted like (f) $5 \alpha$-pregnane-3,20dione, $5 \alpha$-pregnan-3 $\alpha$-ol-20-one; (g) $5 \alpha$-pregnan-3 $\beta$-ol-20-one.

\section{Discussion}

Faecal samples of black rhinoceroses were used to test the possibility of non-invasive endocrine investigations in this species. Monitoring of the oestrous cycle was possible by measuring $20 \alpha$-, Pd- and 20-keto-progestagens; but, in contrast to mares and Przewalski mares (Schwarzenberger et al., 1992), it was not possible by measuring $20 \beta$-progestagens.

The faecal progestagens revealed by the different EIA parallel patterns and low concentrations coincided with mating, thus providing good, indirect evidence that the profiles reflected oestrous cycles. Maximum concentrations of the faecal 20-ketoprogestagens (during the luteal phase) varied more than did those for the 20a-progestagens. 

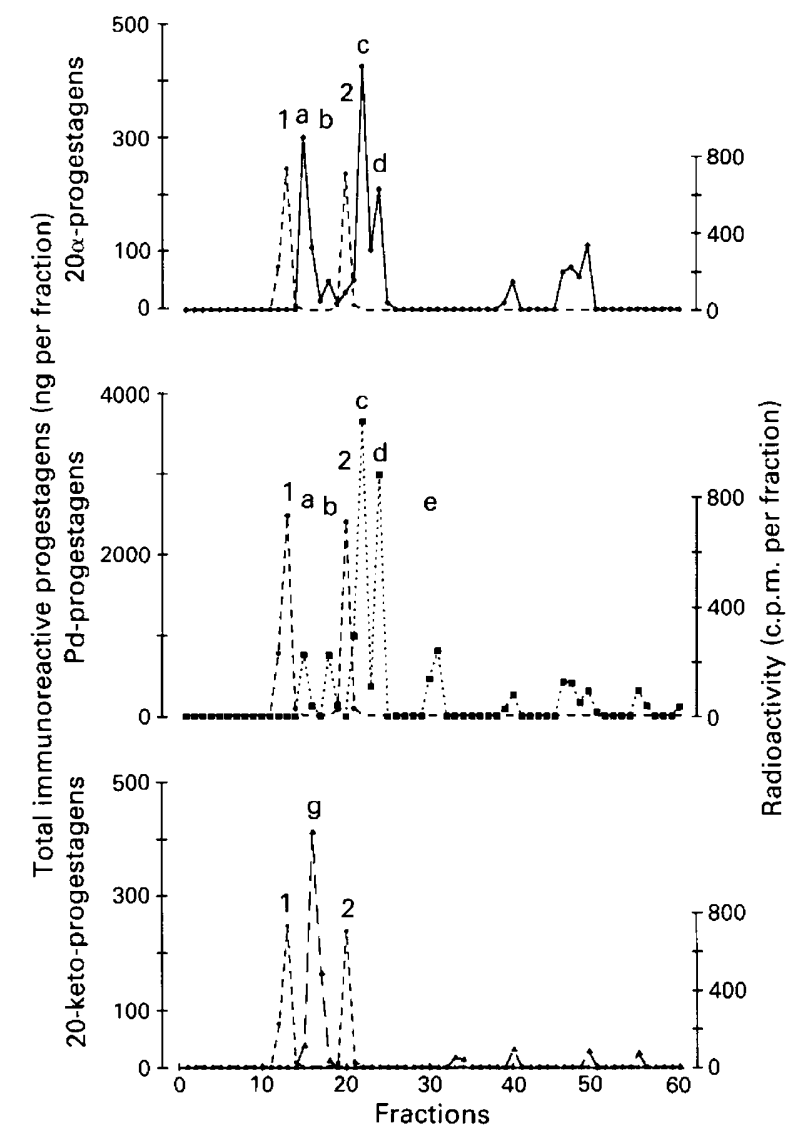

Fig. 4. Total immunoreactive progestagens during the last third of pregnancy in a faecal sample from a black rhinoceros after HPLC separation and subsequent analysis of the fractions with three different

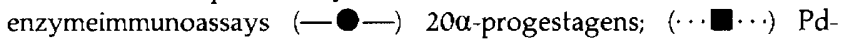
progestagens; (- $\mathbf{\Lambda}--)$ 20-keto-Pgs. Concentrations are ng per fraction calculated for $1 \mathrm{~g}$ of faeces without correction for methodological losses. $\left[{ }^{3} \mathrm{H}\right]$ steroids (- - - - ) determined by liquid scintillation counting. 1: $\left[{ }^{3} \mathrm{H}\right.$ iprogesterone; 2 : $\left[{ }^{3} \mathrm{H}\right]-20 \alpha$-dihydroprogesterone. The retention times of the immunoreactive peaks $(\mathrm{a}-\mathrm{g})$ were compared to those of different steroid standards (a)5- $\alpha$-pregnan-20 $\alpha$-ol-3-one; (b) $5 \beta$ -

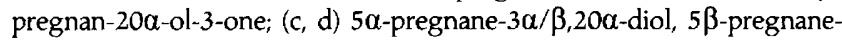
$3 \beta, 20 \alpha$-diol and 5 -pregnene- $3 \beta, 20 \alpha$-diol; (e) $5 \beta$-pregnane- $3 \alpha, 20 \alpha$-diol; whereas the 20 -keto-progestagens eluted like (g) $5 \alpha$-pregnan-3 $\beta$-ol20-one.

Since the samples for this study were collected over periods of more than one year, a compromise on the sampling interval was necessary. Therefore, the duration of the luteal phase could not be determined, but calculation of cycle length was achieved by dividing the number of luteal phases detected into the period over which samples were available. Mean cycle lengths in two animals were estimated as 24 and 26.5 days, respectively. These values are within the range of 17-60 days given by Jarvis (1967), based on behavioural observations. Our data are more comparable to the recent findings of Hindle et al. (1992), who measured 20a-dihydroprogesterone in urine samples of black and white rhinoceroses. Based on two consecutive cycles in one black rhinoceros, these authors described an inter-oestrus interval of 25 days; they also suggested intervals of 32 and 25 days for southern and northern white rhinoceroses, respectively. The mean cycle length in the Indian rhinoceros has been recorded as
$43 \pm 2$ (Kassam and Lasley, 1981) and 48 (range 39-64) days (Kasman et al., 1986), respectively.

In our study, the interval from mating to increasing progestagen values was more than 5 days, whereas Hindle et al. (1992), using urine samples, reported it as 3 days. The intestinal transit time might explain this difference. In mares, a delay of 1-2 days in the changes in faecal progestagen values as compared with plasma progesterone has been reported (Schwarzenberger et al., 1992).

Gestational lengths in two of the animals were 459 and 470 days, respectively, and between 440 and 454 days in the animals, where it was calculated on the basis of faecal progestagen assays. These results agree with the studies of Ramsay et al. (1987), who reported gestational lengths of 438 to 480 days, and with the compiled data from different zoos where it ranged from 419 to 476 days (Jarvis, 1967). It is also comparable to the figure of 450 days given by Schenkel (1990).

Faecal progestagen values increased to luteal phase concentrations within 10 days after fertilization and remained in this range for the first 2 months of pregnancy. This suggests that confirmation of pregnancy, based on analysis of weekly faecal samples is feasible as early as 3 to 4 weeks after mating (see Fig. $1 \mathrm{a}-\mathrm{c})$. Further confirmation is possible by monitoring faecal progestagen values between days 60 and 250 , a period reflecting the onset of placental steroid production. Pregnancy diagnosis using urinary pregnanediol-glucuronide measurements in the Indian rhinoceros is possible 4 months after mating (Kasman et al., 1986; Hodges and Green, 1989), whereas in the black rhinoceros it is possible only from midgestation onwards (Ramsay et al., 1987). High progestagen concentrations in faecal samples between days 200 and 250 are not reflected in urinary pregnanediol-glucuronide concentrations. Nevertheless, the high concentrations of faecal 20 $\alpha$-progestagens and Pd-progestagens at the end of gestation are comparable to the patterns of urinary pregnanediol-glucuronide in Indian (Kasman et al., 1986; Hodges and Green, 1989) and black rhinoceroses (Ramsay et al., 1987; Hodges and Green, 1989). They are also reflected in serum hormone concentrations of black rhinoceroses, where progesterone radioimmunoassay values $>1000 \mathrm{ng} \mathrm{ml}^{-1}$ during the last third of pregnancy were reported (Kock et al., 1991). During the last month of pregnancy analogous peak concentrations of various progestagens in the blood (Hamon et al., 1991; Holtan et al., 1991) and faeces (Schwarzenberger et al., 1991) of mares have been described.

Faecal progestagens declined during the last two weeks of pregnancy, but parturition took place in the presence of significant concentrations. This agrees with the studies of Kasman $e t$ al. (1986), Ramsay et al. (1987) and Hodges and Green (1989), who also reported parturition in rhinoceroses coincident with high concentrations of urinary pregnanediol-glucuronide. However, urinary concentrations dropped to basal values within one day, whereas faecal values declined more slowly to reach basal values within 3 days after parturition. Similar findings were reported for faecal samples of pregnant mares (Schwarzenberger et al., 1991). Again, a delay in excretion of faecal samples may lie in the longer transit time.

Within one month after parturition progestagen values, indicative of the luteal phase, were measured in two animals, suggesting that a post partum oestrus had occurred. However, 
mating or conception is very unlikely at this time, since the birth interval of the black rhinoceros in its natural environment is 3 years (Schenkel, 1990).

After administration of radioactively labelled progesterone to a white rhinoceros the radio-labelled steroids were recovered only as progesterone from the faeces but as progesterone and $20 \alpha$-dihydroprogesterone from urinary samples (Hindle and Hodges, 1990). This is in contrast to our study, in which only small quantities of immunoreactive substances coeluting with $\left[{ }^{3} \mathrm{H}\right]$ progesterone and $\left[{ }^{3} \mathrm{H}\right] 20 \alpha$-dihydroprogesterone were present. However, these results are similar to our previous findings in mares (Schwarzenberger et al, 1991, 1992), where different progestagens with polarities like mono- and dihydroxylated pregnanes were also found.

In faecal samples collected during the oestrous cycle, no immunoreactive substance eluting like pregnanediol was observed, but increasing quantities (Fig. 4, peak 'e') appeared during pregnancy. This is in agreement with studies on urine samples of black rhinoceroses (Ramsay et al., 1987; Hodges and Green, 1989; Hindle et al., 1992). In contrast, measurement of urinary pregnanediol-glucuronide enabled the monitoring of oestrous cycles in Indian rhinoceroses (Kasman et al., 1986); the values during pregnancy in this species were much higher than in black rhinoceroses (Ramsay et al., 1987; Hodges and Green, 1989).

Progesterone, 20 $\alpha$-dihydroprogesterone and pregnanediol were used as standards for the EIA but, as was demonstrated by HPLC, contributed only to a minor extent to the EIA readings. Our results, therefore, should be considered as measuring total immunoreactive progestagens; and although their full identity remains to be established, HPLC separation and subsequent analysis with EIA proved the presence of several immunoreactive progestagens. Furthermore, it was shown that the three EIA used had reasonable specificity in terms of these progestagens, since different elution profiles between the $20 \alpha$ - and Pd-progestagens versus the 20-keto-progestagens were found.

In conclusion, the results of the present study indicate that different EIA with reasonable specificity for progestagens containing either a 20-keto or a $20 \alpha$-hydroxyl group can be used for non-invasive monitoring of endocrine function during the oestrous cycle, pregnancy and the post partum period of black rhinoceroses.

We thank the animal keepers Mr Wielandt, Mr Jahr and Mr Pott for the conscientious collection of the faecal samples; A. Aichinger for excellent technical assistance; P. Samarajeewa and A. G. Kanout for providing the antibodies; E. Möstl for preparation of enzyme labels and the 20-keto-progestagen antibody and the 'L. Boltzmann-Inst. $f$. vet. med. Endokrinologie' for supplies of chemicals and equipment. Development of the EIA was supported by a grant from the 'Austrian Ministry of Agriculture and Forestry' (project no. 489).

\section{References}

Bamberg E, Choi HS, Möstl E, Wurm W, Lorin D and Arbeiter K (1984) Enzymatic determination of unconjugated oestrogens in faeces for pregnancy diagnosis in mares Equine Veterinary Journal 16 537-539
Bamberg E, Möstl E, Patzl M and King GJ (1991) Pregnancy diagnosis by enzyme immunoassay of estrogens in feces from nondomestic species Journal of Zoo and Wildlife Medicine 22 73-77

Choi HS, Kiesenhofer E, Gantner H, Hois J and Bamberg E (1987) Pregnancy diagnosis in sows by estimation of oestrogens in blood, urine or faeces Animal Reproduction Science 15 209-216

Desaulniers DM, Goff AK, Betteridge KJ, Rowell JE and Flood PF (1989) Reproductive hormone concentrations in faeces during the oestrous cycle and pregnancy in cattle (Bos taurus) and muskoxen (Ovibos moschatus) Canadian Journal of Zoology 67 1148-1154

Graham CE, Collins DC, Robinson H and Preedy JRK (1972) Urinary levels of estrogens and pregnanediol and plasma levels of progesterone during the menstrual cycle of the chimpanzee: relationship to the sexual swelling Endocrinology 91 13-24

Hamon M, Clarke SW, Houghton E, Fowden AL, Silver M, Rossdale PD, Ousey IC and Heap RB (1991) Production of 5a-dihydroprogesterone during late pregnancy in the mare Journal of Reproduction and Fertility Supplement $\mathbf{4 4}$ 529-535

Hindle JE and Hodges JK (1990) Metabolism of oestradiol-17 $\beta$ and progesterone in the white rhinoceros (Ceratotherium simum simum) Journal of Reproduction and Fertility 90 571-580

Hindle JE, Möstl E and Hodges JK (1992) Measurement of urinary oestrogens and 20a-dihydroprogesterone during ovarian cycles of black (Diceros bicornis) and white (Ceratotherium simum) rhinoceroses Journal of Reproduction and Fertility $94237-249$

Hodges JK and Green DI (1989) The development of an enzyme-immunoassay for urinary pregnanediol-3-glucuronide and its application to reproductive assessment in exotic mammals Journal of Zoology 219 89-99

Holtan DW, Houghton E, Silver M, Fowden AL, Ousey J and Rossdale PD (1991) Plasma progestagens in the mare, fetus and newborn foal journal of Reproduction and Fertility Supplement 44 517-528

Jarvis C (1967) Tabulated data on the breeding biology of the black rhinoceros (Diceros bicornis) compiled from reports in the yearbook. In International Zoo Yearbook, Vol. 7. p 166 Ed. C Jarvis. The Zoological Society, London

Kasman LH, McCowan B and Lasley BL (1985) Pregnancy detection in tapirs by direct urinary estrone sulfate analysis Zoo Biology 4 301-306

Kasman LH, Ramsay EC and Lasley BL (1986) Urinary steroid evaluations to monitor ovarian function in exotic ungulates: III. Estrone sulfate and pregnanediol-3-glucuronide excretion in the Indian rhinoceros (Rhinoceros unicomis) Zoo Biology 5 355-361

Kassam AAH and Lasley BL (1981) Estrogen excretory patterns in the Indian rhinoceros (Rhinoceros unicomis), determined by simplified urinary analysis American Journal of Veterinary Research 42 251-255

Kirkpatrick JF, Shideler SE, Lasley BL and Turner JW, Jr (1991) Pregnancy determination in uncaptured feral horses by means of fecal steroid conjugates Theriogenology 35 753-760

Klös H-G and Frese R (1991) Introduction to the 4th revised edition of the international studbook of African rhinoceroses. In International Studbook of African rhinoceroses (Diceros bicornis/Ceratotherium simum) No. 4, pp 22-36 Eds H-G Klös and R Frese. Zoologischer Garten, Berlin

Kock N, Morton D and Kock M (1991) Reproductive parameters in free ranging female black rhinoceroses (Diceros bicornis) in Zimbabwe Onderstepoort Journal of Veterinary Research $\mathbf{5 8} 55-57$

Loskutoff NM, Walker L, Ott-Joslin JE, Raphael BL and Lasley BL (1986) Urinary steroid evaluations to monitor ovarian function in exotic ungulates: II. Comparison between the giraffe (Giraffa camelopardalis) and the okapi (Okapia johnstoni) Zoo Biology 5 331-338

Lucas Z, Raeside JI and Betteridge KJ (1991) Non-invasive assessment of the incidences of pregnancy and pregnancy loss in the feral horses of Sable Island Journal of Reproduction and Fertility Suppiement 44 479-488

Messier F, Desauliniers DM, Goff AK, Nault R, Patenaude R and Crete M (1990) Caribou pregnancy diagnosis from immunoreactive progestins and estrogens excreted in feces Journal of Wildlife Management 54 279-283

Möstl E, Nöbauer H, Choi HS, Wurm W and Bamberg E (1983) Trächtigkeitsdiagnose bei der Stute mittels Ostrogenbestimmung im Kot Der Praktische Tierarzt 64 49I-492

Ramsay EC, Kasman LH and Lasley BL (1987) Urinary steroid evaluations to monitor ovarian function in exotic ungulates: V. Estrogen and pregnanediol3-glucuronide excretion in the black rhinoceros (Diceros bicomis) Zoo Biology 6 $275-282$ 
Safar-Hermann N, Ismail MN, Choi HS, Möstl E and Bamberg E (1987) Pregnancy diagnosis in zoo animals by estrogen determination in feces Zoo Biology 6 189-193

Schenkel R (1990) Rhinoceroses, Introduction. In Grzimek's Encyclopedia of Mammals Vol. 4 (Translation of 'Grzimeks Enzyklopädie der Säugetiere'), pp 610-616 Ed. SP Parker. McGraw-Hill Inc., NY

Schwarzenberger F, Möstl E, Bamberg E, Pammer J and Schmehlik O (1991) Concentration of progestagens and oestrogens in the faeces of pregnant Lipizzan, Trotter and Thoroughbred mares Joumal of Reproduction and Fertility Supplement 44 489-499
Schwarzenberger F, Möstl E, Bamberg E and von Hegel G (1992) Monitoring of corpus luteum function by measuring progestagens in faeces of non-pregnant mares (Equus caballus) and Przewalski mares (Equus przewalski) Animal Reproduction Science 29 263-273

Wasser SK, Monfort SL and Wildt DE (1991) Rapid extraction of faecal steroids for measuring reproductive cyclicity and early pregnancy in free-ranging yellow baboons (Papio cynocephalus cynocephalus) Journal of Reproduction and Fertility 92 415-423 